\title{
El suicidio
}

y otros comportamientos

autodestructivos en jóvenes universitarios

de Colombia y Puerto Rico:

acciones, interacciones

y significaciones

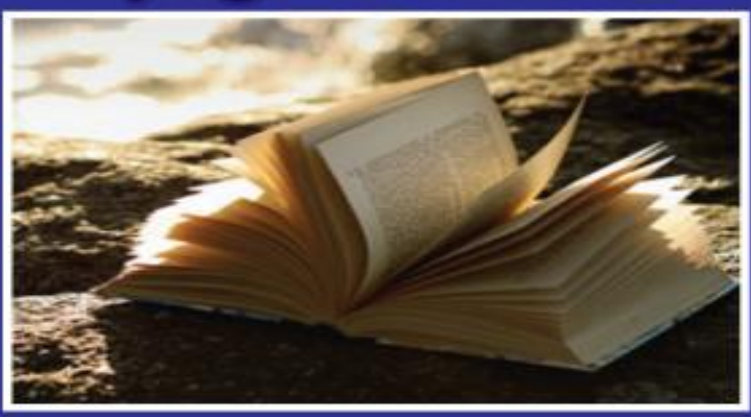

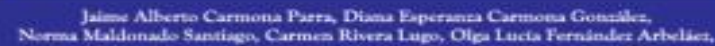

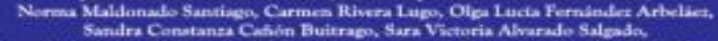

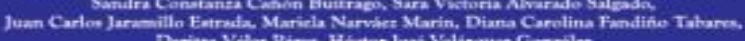

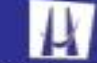

MANBZALES

CAPÍTULO 6. Suicidio y otros comportamientos autodestructivos en jóvenes universitarios: estudio en tres recintos universitarios de tres ciudades de Puerto Rico.

\section{Modelo de citación}

Maldonado Santiago, N., Rivera Lugo, C., Vélez Pérez, D. y Velázquez González, H. J. (2017).

Suicidio y otros comportamientos autodestructivos en jóvenes universitarios: estudio en tres recintos universitarios de tres ciudades de Puerto Rico. En J.A., Carmona, et al. (Comp.). El suicidio y otros comportamientos autodestructivos en jóvenes universitarios en Colombia y Puerto Rico: acciones interacciones y significaciones. (pp. 119-141). Manizales: Universidad de Manizales. 


\section{Suicidio y otros comportamientos autodestructivos en jóvenes universitarios: estudio en tres recintos universitarios de tres ciudades de Puerto Rico}

Norma Maldonado Santiago

Carmen Rivera Lugo

Daritza Vélez Pérez

Héctor José Velásquez González

El presente capítulo contiene resultados de la investigación "Prevención del suicidio en el escenario universitario: un abordaje desde lo psicosocial", desarrollada en Puerto Rico, en colaboración con la realizada en Colombia sobre el tema.

La investigación-acción tuvo como principal propósito asumir el fenómeno del suicidio en adolescentes y jóvenes adultos universitarios, de una universidad privada en el sur de la isla, desde una aproximación psicosocial que trascendiera el acercamiento teórico psicologista que analiza el suicidio desde una postura individualista. En este sentido, la investigación tuvo como objetivo principal conocer y comprender los significados que los participantes adscriben al suicidio, y la manera cómo se construyen esos significados.

El diseño metodológico fue mixto con énfasis en el análisis cualitativo de datos recopilados a través de tres fases, vía entrevistas semiestructuradas y de profundidad, 
y con el apoyo de seis instrumentos utilizados a lo largo del proyecto. Las fases fueron las siguientes:

- $\quad$ Primera Fase - contestar una sección de preguntas dirigidas a recopilar los datos sociodemográficos y un cuestionario de 7 preguntas.

- Segunda Fase - contestar un segundo cuestionario de preguntas abiertas para estudiantes que han realizado algún intento de suicidio desde el comienzo de sus estudios universitarios. De acuerdo con los resulta- dos obtenidos, y si el participante o la participante estaba dispuesto, colaboraría de la tercera fase del estudio

- Tercera fase: participar de una entrevista a profundidad. La entrevista se grabó para transcripción y análisis de contenido, con el consentimiento del participante.

Se administró, además, un cuestionario de preguntas abiertas a los profesionales de las oficinas de los servicios de bienestar universitario para recoger información relativa a intervenciones, desde sus programas, con alguna situación de ideación, intento de suicidio o suicidio, una vez aceptaron participar voluntariamente.

La investigación en Puerto Rico, aquí reportada, corresponde a la Fase 2 del estudio, y la muestra correspondiente de 63 estudiantes, subgraduados y graduados, de tres recintos de la institución universitaria. La muestra incluyó estudiantes de los colegios de Ciencias, Artes y Humanidades, Educación, Administración de Empresas, Escuela de Arquitectura y el Colegio de Estudios Graduados que hubieran presentado en el último año ideaciones suicidas o intentos de suicidio, o bien haber tenido conocimiento cercano del intento de suicidio o el suicidio consumado de un estudiante universitario.

\subsection{Aspectos generales}

\subsubsection{Estudiantes que realizaron al menos un intento de suicidio en el último año}

Con base en los datos obtenidos, 28 estudiantes $(44,4 \%)$ reportaron al menos un intento de suicidio en el último año. De éstos, cuatro (14,3\%) eran varones, mientras que 24 (85,7\%) féminas. A continuación, se expondrán los datos respecto a edades, método empleado, período de la semana, horario y período académico. 
Edad: las edades fluctuaron entre 11 y 28 años. Del total (28), doce (42,8\%) reportaron haber tenido el primer intento entre 11 y 16 años, mientras cinco participantes $(17,8 \%)$ no especificaron la edad. Cuatro estudiantes $(14,2 \%)$ con edades entre los 12 y 20 años reportaron más de un intento.

Método empleado: de los estudiantes participantes que realizaron al menos un intento de suicidio en el último año, doce $(42,8 \%)$ indicaron haber utilizado la automutilación (cortarse con navajas, tijeras, tachuelas, vidrio); once (39,2\%) informaron intoxicación (con medicamentos, cloro, alcohol); tres (10,7\%) por ahorcamiento y asfixia; uno, (3,5\%) tirarse a la carretera y otro (3,5\%) indicó saltar de un auto en movimiento. Vale notar que los métodos más utilizados son automutilación e intoxicación.

Período de la semana: cuatro participantes $(14,2 \%)$ intentaron suicidar- se el día martes; cuatro (14,2\%) jueves; tres (10,7\%) lunes; dos $(7,1 \%)$ miércoles, y dos $(7,1 \%)$ domingo. La frecuencia menor corresponde a viernes y sábado, con un participante por día. Nueve participantes $(32,1 \%)$ no sabían o no recordaban el momento en la semana en que lo intentaron.

Período del día: siete de los participantes (25\%) indicaron algún intento de suicidio en horas de la tarde y de la noche, siendo este período el de mayor frecuencia. El período de menor frecuencia va desde la mañana al mediodía con un total de cinco $(17,8 \%)$. Sin embargo, de los 28 participantes, cuatro (14.2\%) no contestaron. A su vez, cinco (17.8\%) reportaron no saber hora específica.

Período académico: trece de los participantes $(46,4 \%)$ reportaron ha- ber intentado suicidarse durante el semestre académico, cuatro (14,2\%) en vacaciones de verano, y uno $(3,5 \%)$ en vacaciones navideñas. Tres de los estudiantes $(10,7 \%)$ no recordaban el periodo académico y siete $(25 \%)$ no respondieron.

Lugar: Diecinueve $(67,8 \%)$ informaron realizar el intento en su residencia (cuarto, baño, balcón); dos en el hospedaje; dos (7,1\%) en la escuela superior', dos $(7,1 \%)$ en un automóvil; y los cinco restantes, cada uno con un porcentaje de $3,5 \%$, en un sitio diferente: casa de un familiar, en la iglesia, en la universidad, en un río y en Irak.

Así, el primer intento de suicidio ocurrió entre los 11 y 16 años, es decir, durante la adolescencia. Los métodos más utilizados fueron automutilación e intoxicación. El

\footnotetext{
${ }^{1}$ Para estudiantes participantes de primer año, el año anterior corresponde a escuela superior
} 
primer intento ocurrió con más frecuencia los días martes y jueves, en horas de la tarde y la noche, durante el semestre académico y en la propia residencia.

\subsubsection{Estudiantes que han tenido conocimiento de algún suicidio} consumado de un compañero cercano

De los 63 estudiantes que participaron en esta segunda fase, seis ( $9,5 \%)$ contestaron tener conocimiento de compañeros cercanos que se quitaron la vida: dos $(33,3 \%)$ hombres y cuatro $(66,7 \%)$ mujeres.

Edad: Las edades de los estudiantes que se quitaron la vida fluctuaron entre 18 a 22 años, con una edad promedio de 20 años.

Método: De los compañeros cercanos que se quitaron la vida, cuatro (67\%) se ahorcaron; uno se lanzó al vacío y uno desconoce el método utilizado.

Período de la semana: Un estudiante especificó que el suicidio ocurrió el fin de semana, otro informó que fue durante la semana y cuatro no especificaron.

Período del día: Un estudiante informó que el suicidio ocurrió como a las 5 de la tarde, dos informaron que fue en la madrugada, y cuatro no especificaron hora.

Lugar: Tres lo hicieron en su propia casa y tres en lugares diferentes estacionamiento, lugar solitario, un bosque).

En resumen, la edad promedio de los estudiantes que se suicidaron fue de 20 años y el método más frecuente fue el ahorcamiento. Pocos especificaron el día de la semana y hora en que ocurrió el suicidio de un estudiante cercano, pero indicaron que el mismo ocurrió en la propia casa.

\subsubsection{Estudiantes que tuvieron conocimiento de algún intento de suicidio de un compañero cercano}

De los 63 estudiantes que participaron en esta segunda fase, 12 (19\%) contestaron tener conocimiento de compañeros cercanos que intentaron suicidarse: cinco $(41,7 \%)$ hombres y siete $(58,3 \%)$ mujeres.

Edad: Las edades fluctuaron entre los 19 y los 25 años, con una edad promedio de 21 años

Método: Los modos utilizados fueron: cinco cortes de venas, cuatro ingesta de pastillas, dos ahorcamientos; dos lanzamientos a la vía pública y una privación de alimentos. 
Período de la semana: Tres estudiantes cercanos intentaron el suicidio durante la semana, dos durante el fin de semana, dos especificaron que fue miércoles y uno viernes. Cuatro participantes indicaron no saber o recordar el día que ocurrió el intento de un estudiante cercano.

Período del día: Dos intentaron suicidarse en la noche, uno al medio día, uno en la tarde y uno al oscurecer. Siete participantes no saben o no recuerdan el momento del día en ocurrió el intento.

Lugar: Se reportaron siete intentos en la casa, uno en el cuarto, uno en casa de un amigo, uno en Ponce y un participante no sabía en qué lugar lo intentó el compañero cercano.

La edad promedio fue, entonces, de 21 años, y los métodos más frecuentes fueron cortarse las venas e ingesta de pastillas. La mayoría de entrevistados indicó que el intento de suicidio del compañero cercano fue durante la semana e indicó no saber la hora. El lugar más frecuente fue la casa.

\subsubsection{Estudiantes que han presentado ideaciones suicidas}

De los 63 estudiantes que participaron en esta fase del estudio, 17 afirmaron haber presentado ideaciones suicidas en el último año. De ellos, 11 (64,7\%) eran mujeres, cinco $(29,4 \%)$ hombres y de una persona no se identificó su género $(5,9 \%)$.

Edad: Las edades en que aparecieron las primeras ideaciones fluctuaron entre los 11 y 23 años. La distribución fue la siguiente: tres participantes tuvieron su primera ideación suicida a los 13 años, tres a los 16, dos a los 11, dos a los 14, dos a los 17 y dos a los 18 años de edad; un participante a los 21 y uno a los 23. Una persona no contestó.

Método: Los métodos ideados para llevar a cabo el acto fueron: chocar el auto (6) cortarse (4), lanzarse de un lugar elevado (4), intoxicación con pastillas o alcohol (3), utilizar un arma, y sin especificar (1).

Período de la semana: Cuatro participantes indicaron que el día de la semana en que las ideaciones fueron más frecuentes fue domingo, tres el sábado y tres el lunes; dos estudiantes indicaron miércoles, dos jueves y dos viernes. Ninguno indicó tener ideas frecuentes los martes y de una persona no se sabía.

Período académico: Siete estudiantes manifestaron ideaciones suicidas más frecuentes a mitad del semestre, tres al final del semestre y tres en vacaciones de verano; dos estudiantes tuvieron ideaciones más frecuentes durante las vacaciones de navidad y uno al principio del semestre académico. 
Se destaca que las edades más frecuentes para la ideación fueron 13 y 16 años, el método más contemplado fue chocar el carro, el día más frecuente el domingo y durante la mitad del semestre.

\subsection{Acciones, interacciones y significaciones de riesgo}

Central a la investigación y cónsono con la perspectiva teórica del interaccionismo simbólico (Mead, 1999) y el Pensamiento Complejo (Morín, 1998), que posibilitan el abordaje bio-psico-socio-cultural del fenómeno en el que se sostiene la misma, se focaliza en esta sección en los eventos, las relaciones vinculares y las significaciones que los estudiantes participantes expresaron como desencadenantes del comportamiento suicida. Cabe destacar que incluimos en este apartado verbalizaciones de estudiantes que intentaron suicidarse, aquellos que han tenido conocimiento de algún intento, y de suicidio de estudiante cercano, y quienes presentaron ideaciones suicidas durante sus estudios universitarios.

\subsubsection{El papel de las acciones en los comportamientos autodestructivos de estudiantes universitarios}

\subsubsection{Acontecimientos de la infancia y la adolescencia}

Entre los acontecimientos durante la infancia y la adolescencia que desencadenaron el comportamiento suicida, los estudiantes identificaron rechazo, abuso sexual, dificultades en las relaciones familiares y acoso es- colar. Expresiones como: "Desde pequeña fui un error de mi madre y me lo echaba en cara todo el tiempo durante toda mi niñez y adolescencia"; "el ser víctima de "bullying" y más en noveno grado, cuando hice el cambio de escuela privada a pública, donde me tenían de punto a nivel de que no podía más con la frustración y depresión”; “pensé que estaba cansada de cada acto de mis padres, de otros familiares, me afectara tanto, ya no quería seguir órdenes ni llorar por quienes se fueron y no pensaron en mí. Era una niña”; "a los 5 a 6 años una prima me incluía en juegos sexuales masturbándonos; un tío abuelo me tocó".

\subsubsection{Acontecimientos de la vida actual}

Los estudiantes expresaron dificultades en las relaciones familiares, en los vínculos amorosos y de amistad, la situación económica personal y familiar, pérdidas significativas, así como dificultades en el escenario universitario. 


\section{- Dificultades en las relaciones familiares}

En esta investigación se encontraron respuestas que relacionan las interacciones familiares con este tipo de conductas: "Pensaba mucho que no era querido por nadie y culpaba a los demás por todos los errores"; "mi mamá es fuerte de carácter, me comparaba con mi hermana mayor, tenía prejuicios conmigo por mi forma de vestir"; "mis papás se habían enterado de mi relación amorosa con una chica y ellos no aceptaban eso".

\section{- Conflictos en los vínculos amorosos y de amistad}

Las relaciones amorosas, al igual que las familiares, también cumplen el doble papel de ser protectoras o de riesgo para las conductas autodestructivas. En el segundo caso, los estudiantes esgrimieron razones como: "Relación amorosa del cual sufrí infidelidades, abuso sexual y psicológico"; "relación de noviazgo donde era manipulada y maltratada emocionalmente"; "malentendido con unas amistades, dejaron de hablarle y la ignoraban".

\section{- Situación económica familiar y personal}

La situación económica, aunada a otros posibles factores de riesgo, fue el detonante para que este estudiante intentara suicidarse, pues como él mismo lo expresa: "Me sentía como una carga económica para mi familia."

\section{- Pérdidas significativas}

Las pérdidas de personas, animales o cosas, representan un factor de riesgo cuando son significativas para la persona que las padece. Se encontraron respuestas como: "La muerte de mis abuelos..."; "la pérdida de su perrita".

\section{- Dificultades en el escenario universitario}

La universidad, que es el escenario donde pasan la mayor parte de su tiempo los estudiantes, presenta múltiples escenarios para los jóvenes, como lo expresan algunos de ellos: "problemas con un profesor de la institución que me prejuiciaba de ser lo que no soy"; "el hecho de no ver frutos en cuanto a los estudios".

\subsubsection{Acontecimientos sin indicar periodo específico de la vida}

Se reportaron experiencias de violencia sin especificar período en que ocurrieron: "Toda la vida le dijeron burro y él se convenció que era una persona tonta"; "fui violado por mi hermano". La Tabla 7 sintetiza esta información. 
Tabla 7.

Acontecimientos o situaciones de riesgo relacionados con conductas autodestructivas

\begin{tabular}{|c|c|c|}
\hline $\begin{array}{l}\text { Ubicación temporal de la } \\
\text { situación o el acontecimiento }\end{array}$ & $\begin{array}{c}\text { Ámbito en el que se presenta la situación o } \\
\text { el acontecimiento }\end{array}$ & $\begin{array}{l}\text { Frecuencia y } \\
\text { porcentaje }\end{array}$ \\
\hline $\begin{array}{l}\text { Acontecimientos de la infancia y } \\
\text { la adolescencia }\end{array}$ & & $13(16,3 \%)$ \\
\hline \multirow{5}{*}{ Actual } & Dificultades en las relaciones familiares & $28(35,0 \%)$ \\
\hline & $\begin{array}{l}\text { Conflictos en los vínculos amorosos y de } \\
\text { amistad }\end{array}$ & $10(12,5 \%)$ \\
\hline & Situación económica familiar y personal & $5(6,25 \%)$ \\
\hline & Pérdidas significativas & $4(5,0 \%)$ \\
\hline & Dificultades en el escenario universitario & $5(6,25 \%)$ \\
\hline $\begin{array}{l}\text { Acontecimientos sin indicar } \\
\text { periodo específico de la vida }\end{array}$ & & $9(11,3 \%)$ \\
\hline No contestaron o no sabían & & $6(7,5 \%)$ \\
\hline Total & & $80(100 \%)$ \\
\hline
\end{tabular}

En resumen, situaciones de abuso y negligencia, y dificultades en las relaciones familiares, situaciones en la infancia y adolescencia y conflictos en los vínculos amorosos y de amistad, fueron señalados como los acontecimientos detonantes del comportamiento suicida.

\subsubsection{El papel de las interacciones o vínculos}

Las interacciones que se establecen con unos otros significativos (familia, madre, padre, pareja, amistades), según los participantes, juegan un papel en propiciar o empujar comportamientos suicidas.

\subsubsection{La familia}

Varias de las respuestas de los estudiantes relacionaron situaciones familiares con sus conductas autodestructivas: "en ese momento en que se nubló mi mente pensé que podía salir de todo de una forma rápida y así lograría la felicidad de ellos [mi familia]". "mis padres no me soportan; soy una carga para ellos"; "mi familia materna me discrimina por creer que soy de cierta orientación sexual y me aislaron de mis demás primos"; "la persona se sentía rechazada por el resto de la sociedad, aunque en general eran compañeros de clase, y familiares y no toda la sociedad".

\section{- Referencias a la madre}

Se encontraron referencias a la relación como la madre, como factor que influyó en la decisión de autolesionarse: "Mi mamá fue la clave importante en mi decisión, su indiferencia y rechazo me llevaron al borde"; "como no tengo una buena relación con 
mi madre, ella como el "bullying” en mi casa, me llevó a un punto donde me cansé de vivir y quería morir."

\section{- Referencias al padre}

La relación con el padre también representó factor de riesgo para un estudiante: "Ahora que puedo pensar con claridad, es porque mis padres se divorciaron y en ese momento mi padre se olvidó que tenía hijos y aunque lo veía se mostraba como si no tuviera ningún sentimiento hacia nosotros."

\section{- Referencias a la pareja}

Como lo reporta la literatura, las relaciones amorosas ocupan uno de los primeros lugares dentro de los factores de riesgo para los comportamientos autodestructivos. Varios estudiantes así lo corroboran con sus testimonios: "Relación amorosa con un chico obsesivo-compulsivo y abusivo. Con el sufrí de chantajes, infidelidades y abuso sexual y psicológico...”; “mi ex, porque se las pegué con una mujer y me dijo mil cosas"; "tuve una pelea con mi pareja y nos dijimos cosas feas. Nos dejamos y como no podía con el dolor tomé frascos de pastillas, las mezclé y me las tomé".

\section{- Compañeros/as y amistades}

Llama la atención en este estudio que para los estudiantes tuvo mayor peso la relación con sus amigos en la decisión de autolesionarse, que con su pareja (11 y 5 casos respectivamente. De ello dan cuenta los siguientes testimonios: “... tener que afrontar la muerte de tu mejor amigo"; “... compañeros de equipo deportivo, amistades que dieron la espalda, fue bien significativo en mi intento"; "la persona se sentía rechazada por el resto de la sociedad, aunque en general eran compañeros de clase, y familiares y no toda la sociedad".

A continuación, una síntesis de frecuencia de las respuestas asociadas a los vínculos que empujan a comportamiento suicida.

En síntesis, las relaciones familiares son el vínculo identificado con más frecuencia que empuja al comportamiento suicida. Otros vínculos que los estudiantes mencionaron con frecuencia fueron con los compañeros y amistades (21\%) y, en menor proporción, la relación de pareja (10\%). Es pertinente señalar que los participantes indicaron que fueron varios los vínculos que influyeron en sus comportamientos autodestructivos, y es por ello que se presentan las verbalizaciones por separado. 
Tabla 8.

Vínculos que empujan al comportamiento suicida

\begin{tabular}{llr}
\hline \multicolumn{1}{c}{ Ámbito y porcentaje } & \multicolumn{1}{c}{ Actores } & Frecuencia \\
\hline & El grupo familiar & 24 \\
& Madre & 5 \\
La familia & Padre & 4 \\
& Hermano (uno o varios) & 1 \\
& Abuelos & 1 \\
\hline Subtotal & & $35(67,0 \%)$ \\
\hline La pareja (10\%) & & $5(10,0 \%)$ \\
\hline Compañeros y amistades (21\%) & & $11(21 \%)$ \\
\hline Sin especificar $(2 \%)$ & & $1(2,0 \%)$ \\
\hline Total (100\%) & & $52(100,0 \%)$ \\
\hline
\end{tabular}

\subsubsection{Significaciones}

Uno de los objetivos de la investigación realizada fue el poder aproximarse a los significados que los participantes adscribieron a las ideaciones y a los intentos de suicido. Las narrativas aportadas por los estudiantes, en el instrumento dos, se analizaron y agruparon por campos temáticos. Este trabajo permitió situar seis grandes grupos. En el grupo más numeroso el comportamiento autodestructivo se asocia con significaciones relativas a escapar de una situación de presión insoportable, liberarse de una situación de opresión o descansar de algo que agobia al joven. En el segundo grupo de narrativas el comportamiento autodestructivo aparece asociado a pensamientos de autodevaluación, mientras que, en el tercer grupo, las narrativas aparecen vinculadas con significaciones de abandono, soledad y desamor, altamente cargadas de tristeza. Un cuarto grupo significa las acciones autodestructivas como vinculadas con una decepción radical de un otro significativo. El quinto y sexto grupo de narrativas aluden a la idea de falta de sentido de la vida y a la idea de quitarse la vida con miedo al acto, sin otras significaciones asociadas respectivamente

\subsubsection{Abandono, soledad y desamor}

Un tercer grupo semántico de narrativas corresponde a las acciones autodestructivas vinculadas con el tema del abandono, la soledad y el desamor. Las ideaciones suicidas y los intentos de suicidio aparecen en este caso como una 
respuesta a la falta de cuidado y atención por parte del otro o de los otros. Mientras que en la categoría anterior el otro se hace insoportable por su extrema exigencia, en este caso se sustrae radicalmente dejando al joven sin un sostén simbólico que le permita afirmarse en el mundo: "se sentía sola y abandonada, tenía poca interacción con sus amistades"; "el no sentirme querida por las personas que me rodean”; “...mis pensamientos eran que nadie me quería, que no me soportaban"; "en ningún momento tuve alguna clase que me que me hiciera llegar un mensaje de soporte o un mensaje que hiciera reflexionar lo que en el pasado hice mal"; "tenía problemas en su casa y tuvo una ruptura con el novio".

En algunos casos, en la misma narrativa se encuentra la significación de abandono y la relacionada con el alivio, lo cual no es extraño por la vecindad semántica que ya señalamos: "mi amigo estaba triste porque se dejó de la novia y tenía problemas en su casa y estaba cansado y quería quitarse la vida, y me seguía repitiendo si no muero hoy, muero mañana".

\subsubsection{Alivio, solución radical o liberación de alguna forma} de sufrimiento

Dentro de esta categoría, en la que el acto suicida se asocia con una idea de evitar algo que ocasiona un profundo malestar, es interesante observar dos matices. El más generalizado se refiere al suicidio como alivio de una situación de presión agobiante: "y como no podía con el dolor, tomé frascos de pastillas las mezclé y me las tomé"; "el intento de suicidio como una forma en la que esperaba terminar con el trastorno obsesivo compulsivo"; "la acumulación de tanta presión que ella tenía no la podía superar. Hay personas que no pueden con tantas cargas: "el estrés familiar y el noviazgo lo llevó a querer morir"; "en verdad que estoy que no aguanto más, siento demasiada presión y siento que me voy a colgar en mis clases"; "presión de familiares en cuanto a sus estudios, así como el estrés de tener que mantener las buenas notas según sus expectativas y las de las personas cercanas a esas personas"; "formé parte del programa de honor de la universidad y el programa binario de medicina, pero nunca sentí que se le diera atención al estrés"; "se comentaba que la carga académica para el programa que se encontraba cursando era muy fuerte. Pero sus amistades decían que él era muy inteligente y que ese no sería un problema para él."

Un segundo matiz ligeramente diferente, que forma parte de esta categoría, también tiene el efecto del alivio, aunque enfatiza el escape o la liberación: "que 
todos los problemas que tenía en ese momento no tenían solución [...] lo veía como una alternativa de liberar todo"; "pensé que nada valía la pena, mejor acabarlo todo y que era mejor acabarlo todo para solucionar las cosas de una vez"; "fue maltratada y, pues, lo vio como una forma de escape"; "yo entiendo que era como un pájaro que quería volar, libertad"; "liberarme de la ansiedad, el estrés, el acoso de mi madre"; "hubo veces en las que pensé que una solución rápida a mis problemas sería esa"; "muchas veces las personas cometen suicidio por liberarse de una persona o problema".

\subsubsection{Decepción radical o desengaño de una persona significativa}

Un cuarto grupo de narrativas asocia el suicidio con una decepción radical de un otro significativo o de los otros como conjunto. Podría decirse que, en ambos casos, el otro se mantiene en una posición "de superioridad" frente al joven que realiza el acto autodestructivo, bien sea desde la posición de quien exige y tiraniza o desde la posición de quien abandona y niega su cuidado. Vale notar que, en el tercer grupo, sin embargo, el otro cae de esa posición "de superioridad", debido a la decepción que provoca en el joven y el significado que se asocia con el acto autodestructivo, como una forma de castigo o sanción a ese otro, aún pagando el precio de la propia vida: "... lamentablemente hubo maestros que me quitaron el ánimo porque no era lo que esperaba..."; "en realidad, cuando pensaba en mis padres sentía más curiosidad de cómo ellos reaccionarían a mi muer- te"; "tenía problemas en su casa y tuvo una ruptura con el novio"; "intolerancia de otros, presión, discriminación que llevó a la persona a no poder más"; "pensaba que su papá también se había divorciado de ella..."; "porque ella también era la nena de papi y creía que el papá la rechazaba [por el divorcio]”.

En algunos casos la expresión no está exenta de ironía: "en ese momento en que se nubló mi mente pensé que podía salir de todo de una forma rápida y así lograría la felicidad de ellos".

\subsubsection{Ideas de autodevaluación o autodenigrantes}

El segundo grupo de narrativas incluye expresiones que apuntan a significaciones de falta de valor propio o baja autoestima asociadas a situaciones familiares, en particular a dificultades en las relaciones parentales y de pareja, que generan tensión emocional, pensamientos derrotistas y de desesperanza: "falta de 
valor, como si no fuera suficiente, como poca cosa"; "nadie me quiere, todo siempre es mi culpa [...], si acabo con mi vida le hago un favor a la sociedad"; "desde pequeña fui el "error" de mi madre y me lo echaba en cara todo el tiempo..."; "me sentía inferior por causa de maltrato, violencia doméstica y condición mental”; “... el que toda su vida le dijeron burro y él se convenció de sí mismo que era una persona tonta”; "pensaba tal vez que tenía demasiadas presiones y que al final terminaría siendo un perdedor por no lograr sus metas..."; "un familiar de la persona le dijo que era decepción como persona"; “... pensamientos de que no vale y que el mundo estaría mejor sin ella"; "se sentía como estorbo con sus amistades"; lo tenían en un estado que pensaba que él no servía para nada, que era bruto, un vago..."; "siempre me comparaba con mi hermana".

\subsubsection{La idea de la falta de sentido de la vida}

Son diversos los campos de sentido con los que se puede articular un suicidio, un intento o una ideación suicida. Las respuestas a la significación relacionadas con el sin sentido o la falta de sentido, aunque aparecen con menos frecuencia, son expresadas de manera contundente: "perdí la fe, espíritu, en ser feliz"; “... no quería responsabilidades y no le encontraba motivo a la vida".

\subsubsection{La idea de suicidarse y el miedo al acto sin otros}

significados asociados

"Yo no puedo hacer ésto..., pero es que no quiero seguir viviendo... una lucha interna"; "en realidad me abundó el miedo a dejar de existir en la tierra, no de vivir, porque realmente no quería vivir".

\subsubsection{Otras respuestas}

En algunos casos, la redacción hace difícil poder situar una narrativa en alguno de los grandes grupos semánticos identificados: "El yo sentir que mi vida cuando era pequeña sería color de rosa y luego ese divorcio me sacó de mi burbuja”.

En la Tabla 9 aparece un resumen de la frecuencia de respuestas en torno a los temas principales en las significaciones que empujan al comportamiento suicida. 
Tabla 9.

Significaciones asociadas con comportamientos autodestructivos en estudiantes universitarios portorriqueños

\begin{tabular}{lc}
\hline \multicolumn{1}{c}{ Tema principal de las significaciones } & $\begin{array}{c}\text { Número de } \\
\text { respuestas y \% }\end{array}$ \\
\hline Alivio, liberación, solución radical & $15(34,9 \%)$ \\
Pensamientos de autodevaluación & $11(25,6 \%)$ \\
Soledad, desamor y depresión & $6(14,0 \%)$ \\
Decepción radical: que puede ser de la pareja, de los padres, del ser humano & $6(14,0 \%)$ \\
en general, o del mundo. & $2(4,7 \%)$ \\
La idea de la falta de sentido de la vida & $2(4,7 \%)$ \\
La idea de quitarse la vida y el miedo al acto sin otras significaciones & $1(2,3 \%)$ \\
asociadas & $43(100 \%)$ \\
\hline Otras respuestas & \\
\hline Total &
\end{tabular}

\subsection{Acciones, interacciones y significaciones protectoras ante comportamientos autodestructivos en estudiantes universitarios portorriqueños}

En esta sección se exponen las acciones, relaciones vinculares y significaciones que los estudiantes participantes expresaron como protectoras/ preventivas de comportamientos suicidas. Son las voces de aquellos que intentaron suicidarse, que han tenido conocimiento de algún intento y de suicidio de estudiante cercano y que presentaron ideaciones suicidas durante sus estudios universitarios.

\subsubsection{Acciones que evitaron el suicidio y le ayudaron a la persona a afirmarse en la vida}

Con relación a las acciones, eventos y hechos, se incluye en la Tabla 10 el tipo de acontecimiento y la frecuencia de las respuestas. Es preciso destacar que las acciones señaladas por los estudiantes como protectoras del comportamiento suicida, están asociadas con mayor frecuencia a las relaciones familiares, de amistad y consigo mismo. 
Tabla 10.

Hechos protectores ante las conductas autodestructivas en estudiantes portorriqueños

\begin{tabular}{llr}
\hline \multicolumn{1}{c}{ Relaciones } & \multicolumn{1}{c}{ Tipo de acontecimiento } & $\begin{array}{r}\text { Número de } \\
\text { respuestas y } \%\end{array}$ \\
\hline \multirow{2}{*}{ Familiares } & Apoyo familiar & 1 \\
& Su mamá & $2(5,0 \%)$ \\
\hline Subtotal & \multicolumn{1}{c}{ Tener invitaciones a salir } & 1 \\
\hline \multirow{2}{*}{ Amistad } & Recibir llamadas y demostraciones de afecto & 4 \\
\hline Subtotal & & $5(12,5 \%)$ \\
\hline & Clases de zumba & 1 \\
& Ayuda espiritual de un sacerdote & 4 \\
& Ir a servicios religiosos en la iglesia & 3 \\
& Acciones benéficas y trabajo comunitario & 3 \\
& Visitar a grupos de jóvenes & 2 \\
& Trabajar en la iglesia como guía juvenil & 1 \\
Consigo mismo & Ayuda profesional en salud mental & 7 \\
& Tomar cursos de psicología & 2 \\
& Participar de talleres de arte y desarrollo & 1 \\
& profesional & 2 \\
& Grupos de organizaciones estudiantiles & 1 \\
& Cambio de institución universitaria y carrera & 6 \\
\hline Subtotal & profesional & $33(82,5 \%)$ \\
\hline Total & Entretenimiento (ir al cine, a la playa con el & $40(100 \%)$ \\
\hline
\end{tabular}

\subsubsection{Interacciones protectoras ante los comportamientos autodestructivos}

\subsubsection{Vínculo con la familia como conjunto}

La familia -decíamos- puede ser para uno de sus miembros un factor de riesgo o protector, de acuerdo con las vinculaciones y significaciones que le asigne a la relación con ellos. En este caso, se reportan las razones que adujeron los estudiantes que consideraron que ese vínculo actuó como factor protector ante las ideaciones suicidas: "Sólo pensaba en mi madre y mis hermanas, el dolor que les ocasionaría"; "mi familia, papi, mami y mi hermana me ayudaron muchísimo, especialmente mami"; "sus padres lo vinieron a visitar. Esto le cambió la vida ya que vio que sus padres lo quieren”; "pensar en cómo afectaría a mi familia y lo triste que se sentirían y la culpa que mi madre sentiría, fue lo que evitó que lo hiciera". 


\subsubsection{Vínculo con la madre}

Algunos indican como factor protector el vínculo con la madre: "mi mamá, aunque fue muy fuerte para ella, me ayudó a salir de donde estaba"; "siempre he dicho que mi mamá es la única razón por la cual yo no llegue a más, ella es una persona bien cristiana y ponerme a pensar en todo lo que ella me enseñó era lo me detenía a seguir".

\subsubsection{Vínculo con hermano o hermana}

La relación con los hermanos también actúa como factor protector: "recuerdo haber pensado en lo mucho que me había afectado la muerte de mi amigo que se suicidó, su hermana gemela sufría mucho y hablaba de él constantemente. Pensé en lo mucho que me necesita mi hermana menor"; "en realidad creo que lo único que ha parado ha sido el daño que le haría a mis hermanos, en especial a mi hermana menor..."; "supongo que el amor que le tengo a mi hermano, el saber que me necesitaba, logró que no pasara"; "el hermano mayor de la muchacha fue un vínculo fundamental para que ella superara el intento".

\subsubsection{Vínculo con la pareja}

Otro de los vínculos que actúan como factor protector ante las conductas autodestructivas es la pareja, como lo expresaron los estudiantes: "mi relación con mi novio, que siempre me da algo que debatir o algo en que pensar (mi novio es muy listo en este sentido. Siempre me da una buena conversación)”; “... su expareja le hizo comprender que la amaba... y nosotros sus amigos estuvimos dispuestos a escucharla sin juzgarla".

\subsubsection{Vínculo con compañeros y amistades}

Al igual que la pareja, los compañeros y amigos representaron, en este estudio, uno de los mayores factores protectores ante los comportamientos autodestructivos. Como lo refirieron: "una amiga me hizo reír"; "cada vez que pensaba en morir, recordaba a mis buenos amigos y el daño que les haría"; "muchos compañeros lo ayudamos y le dimos esperanza de vida para que se olvidara de los problemas..."; “... mis amistades cibernéticas o grupo con el que juego en línea”.

\subsubsection{Vínculo profesional y religioso}

Contar con el apoyo de una persona que pueda brindar apoyo y asesoría en momentos críticos, es otros de los factores que contribuye a evitar las conductas 
autodestructivas. En este caso, desde lo profesional y lo religioso, los estudiantes encontraron esa ayuda: "una profesora del centro de consejería donde trabajo, por estudio y trabajo"; "fui a confesarme con un excelente sacerdote, me ayudó a reconsiderar la idea y las consecuencias de ello"; "la familia y los sacerdotes que viven en la casa. La familia siempre me apoyó, era una fuente de tranquilidad".

\subsubsection{Otros vínculos}

Ya se mencionó que un vínculo actúa como factor protector cuando éste es significativo para la persona: “Pensaba en quién cuidaría a su perrita”.

Entre los vínculos más significativos que rescatan se encuentran los familiares (madre, hermanos), amistades, relaciones de pareja y vínculos con personas religiosas (abuela pastora, sacerdote). Cabe destacar que las mascotas influyeron en la prevención del suicidio en dos estudiantes.

La Tabla 11 recoge las frecuencias que dichos vínculos fueron mencionados como aquellos que los rescataron de comportamientos suicidas

Tabla 11.

Interacciones protectoras ante las conductas autodestructivas en estudiantes portorriqueños

\begin{tabular}{llr}
\hline \multicolumn{1}{c}{ Ámbito } & \multicolumn{1}{c}{ Vínculo } & Frecuencia y \% \\
\hline \multirow{2}{*}{ Pareja y amistades } & Pareja & 6 \\
& Compañeros o amigos & 16 \\
& Amistades cibernéticas & 1 \\
\hline Subtotal & Familia como conjunto, o referencia a varios & $23(40,35 \%)$ \\
\hline & de sus integrantes & 11 \\
Familia & Mamá & 6 \\
& Hermanos & 7 \\
& Abuelos & 2 \\
\hline Subtotal & Tía & 1 \\
\hline Profesional & & $27(47,30)$ \\
\hline \multirow{2}{*}{ Religioso: $7 \%$} & Profesora & $1(1,75 \%)$ \\
\hline Subtotal & Sacerdote & 2 \\
\hline Otros: $4 \%$ & Líderes de la iglesia & 1 \\
\hline Total: $100 \%$ & Pensar en Dios & $4(7,10 \%)$ \\
\hline
\end{tabular}




\subsubsection{Significaciones protectoras ante los comportamientos autodestructivos}

Una vez analizadas las respuestas que aportaron los estudiantes a la pregunta relacionada con las significaciones o ideas que les ayudaron a afirmarse en la vida, se organizaron en seis grupos de acuerdo con las siguientes categorías.

\subsubsection{Pensamientos autocríticos que le permitieron adoptar una posición alternativa al suicidio}

Algunas de las narrativas de los jóvenes, en torno a las ideas que les ayudaron a abandonar el suicidio y a afirmarse en la vida, aluden a pensamientos alternativos que ellos mismos oponen a sus ideaciones y planes suicidas. Es precisamente a la capacidad autocrítica que tenemos los seres humanos, de tomar distancia de nuestras propias ideas y construir una especie de diálogo o discusión interna, que podemos llegar a cambiar radicalmente el punto de vista frente a un determinado asunto. Veamos algunos ejemplos: "el pensar que muchas personas estarían pasando por situaciones mucho más difíciles, me hacía y hace darme cuenta del error que cometía al tener esos pensamientos negativos"; "ideas que ha aprendido en el transcurso de su mejora... así como poco a poco, según me dice, ha cambiado su perspectiva de lo que es la vida y su pro- pósito en ella..."

Esta capacidad autocrítica puede recaer sobre las consecuencias de las propias ideas, sobre la propia salud: "uno se deteriora de pensar en morir". Puede, también, tomar un matiz claramente pragmático: "que tenía que buscar el lado bueno de mis problemas, que quitarme la vida no es una solución a mis problemas". Puede, además, expresarse como un análisis de las razones y las circunstancias que influyeron en el proceso de construcción de las ideaciones o el intento de suicidio: "El intento, es francamente, una desesperación por falta de información, opciones que uno no tiene en ese momento tan crítico en la vida. Son muchos los factores"; "yo estaba mal por lo que habría cometido y eso me llevaba a pensar y actuar como lo hice".

También el centrar la atención en aspectos presentes, pero desatendidos, como puede ser el amor propio: "En realidad no recuerdo, pero creo que el amor a mí misma logró detenerme y vomitar antes que fuera tarde"; "luego de tocar fondo se dio cuenta de que su vida vale más que cualquier situación, que tiene que ser fuerte...”. 


\subsubsection{Significaciones teleológicas}

La capacidad de la ilusión, que se manifiesta en la posibilidad de generar representaciones positivas relacionadas con el futuro, aparece como un elemento que contribuye a la protección frente a los comportamientos autodestructivos: "pensar en cómo sería mi vida si no me quito la vida, cómo sería si yo supero todo esto"; "pensar que podía superarlo, que todavía podía formarme como persona, tener un mejor futuro"; “... pienso en que seré una profesional próximamente. Pienso en ese futuro que estoy construyendo hoy con mis estudios. Además, de que los estudios son el foco de distracción ante todo problema".

\subsubsection{Ideas relacionadas con la familia}

Las ideas relacionadas con vínculos afectivos, profundos y positivos aparecen también en las narrativas de los estudiantes, como respuesta a la pregunta por las significaciones que les ayudaron a neutralizar las ideas autodestructivas y a afirmarse en el deseo de vivir. Estas ideas se refieren al grupo familiar como conjunto: "pensaba en toda la película de todas las personas tristes por mi muerte y se me quitaba”.

También se pueden referir a un integrante de la familia en particular, vinculándolo con la idea de un ser superior: "y en algún momento me di cuenta que le iba a faltar tanto a mi mamá como a Dios, que si Dios se tomó el tiempo en darme vida como yo era tan mala que le iba a despreciar el hermoso regalo de crearme. Me llegó el pensamiento de ¿qué hago?".

Puede aparecer, además, referido a los hermanos y a las hermanas, ligado a un deseo de protegerlos: "al llevar a cabo el acto y fallar, pudo ver el dolor que les causó a los [hermanos] y entendió que ella sí le importa a alguien... creo que lo que la mantiene con vida es la idea de que sí la necesitan y es útil e importante para alguien"; "mi hermano me preocupa, quién lo va a cuidar y proteger".

En adición, puede tomar la forma de la vergüenza por defraudar a los padres: "lo único que pensaba una y otra vez era que defraudaba a mis papás"

\subsubsection{Ideas relacionadas con las relaciones de pareja, los amigos y compañeros}

Éstas aparecen en las narrativas de los estudiantes como elementos que contribuyeron, en su momento, a la protección frente a las ideaciones o intentos de suicidio. Además, en ellas encontramos diferentes matices: por ejemplo, el pudor 
frente al impacto que la consumación del suicidio puede generar en alguno de ellos o en todos como conjunto: "también estando ahí, con el cinturón en el cuello, me dio miedo de que mi roommate entrara y me hiciera pasar una vergüenza. Si me veía así, hubiera sido humillante".

Asimismo, puede tomar el matiz del deseo de ganarse el reconocimiento de ellos: "mi única idea después del intento, fue que debía de mantenerme viva para poder demostrar de lo que soy capaz". Incluso, la idea de convertirse en un apoyo para los otros: "el propósito de la vida y lo que es desde una nueva perspectiva, que es abstracta dirigida a ayudar a los demás y ya no más centrada solo en esa persona ya que se siente más fuerte en su personalidad"

\subsubsection{Idea de trascendencia}

Los investigadores del fenómeno del suicidio coinciden en señalar la religiosidad como un factor protector en las personas creyentes (Taha, Florenzano, Sieverson, Aspillaga, \& Alliende, 2011; WHO, 2014). Algunas de las narrativas de los estudiantes se orientan en esta dirección. En algunos casos destacan el efecto que produce en ellos su convicción de la superioridad de las ideas religiosas sobre la representación de los problemas de este mundo: "sólo pude dejar mis ideas suicidas cuando encontré un mayor propósito para vivir".

En otros casos acentúan su idea de la deuda de gratitud con el ser supremo y las consecuencias para reorientar el rumbo de sus vidas: "pensé en lo mucho que Jesús sufrió por darnos vida, y yo siendo un malagradecido andaba buscando la muerte. Sentí mucho arrepentimiento por mis actos, pero a la vez sentí una gran liberación. Cada día trabajo más en la iglesia, sirviendo como guía para otros jóvenes, lo cual me da propósito...".

\subsubsection{Otras respuestas}

Los estudiantes expresaron también narrativas referidas a temas disímiles como el miedo a la muerte, el deseo de ayudar a los animales y una afición como el baile: “en realidad me abundó el miedo de dejar de existir en la tierra, no de vivir, porque realmente no quería vivir"; "el hecho de no existir me ayudó a recapacitar"; "poder ayudar me motiva, poder ayudar sobre todo a los animales"; "su amor por el baile lo llevó a que siguiera viviendo“.

La Tabla 12 resume las significaciones protectoras hasta aquí presentadas. 
Tabla 12.

Significaciones protectoras ante los comportamientos autodestructivos en estudiantes universitarios de Puerto Rico

\begin{tabular}{|c|c|c|}
\hline Tópicos & Ejemplos de las ideas o significaciones & $\begin{array}{l}\text { Frecuencia de } \\
\text { respuestas y \% }\end{array}$ \\
\hline $\begin{array}{l}\text { Pensamientos autocríticos } \\
\text { que le permitieron } \\
\text { adoptar una posición } \\
\text { alternativa al suicidio }\end{array}$ & $\begin{array}{l}\text { - Comparaciones con la situación de otras } \\
\text { personas que podían estar afrontando } \\
\text { situaciones más difíciles } \\
\text { - Los efectos de las ideaciones suicidas sobre la } \\
\text { propia salud } \\
\text { - Los resultados prácticos de las ideaciones } \\
\text { suicidas } \\
\text { - Análisis crítico del origen de los intentos de } \\
\text { suicidio } \\
\text { - Ideas relacionadas con la propia autoestima. }\end{array}$ & $9(33,33 \%)$ \\
\hline $\begin{array}{l}\text { Significaciones } \\
\text { relacionadas con } \\
\text { expectativas de futuro: }\end{array}$ & $\begin{array}{l}\text { - Ideas de un futuro deseable } \\
\text { - Ideas relacionadas con la propia formación } \\
\text { - Pensamientos relativos al desempeño profesional }\end{array}$ & $3(11.11 \%)$ \\
\hline $\begin{array}{l}\text { Ideas relacionadas con la } \\
\text { familia }\end{array}$ & $\begin{array}{l}\text { - La familia como conjunto } \\
\text { - Las figuras parentales } \\
\text { - La madre o el padre independientemente } \\
\text { - Hermanos y hermanas }\end{array}$ & $6(22.22 \%)$ \\
\hline $\begin{array}{l}\text { Ideas relacionadas con } \\
\text { las relaciones de pareja, } \\
\text { los amigos y } \\
\text { compañeros, incluidas } \\
\text { decisiones de cambios en } \\
\text { este campo }\end{array}$ & $\begin{array}{l}\text { - La idea de ayudar a los demás } \\
\text { - La idea del reconocimiento por parte de las } \\
\text { amistades, compañeros y compañeras } \\
\text { - Los escrúpulos y la vergüenza por lo que pudieran } \\
\text { pensar las amistades si consumaba el suicidio }\end{array}$ & $3(11.11 \%)$ \\
\hline Idea de la trascendencia & $\begin{array}{l}\text { - Un propósito más elevado que los problemas del } \\
\text { mundo. } \\
\text { - El sentimiento de deber la vida a un ser superior }\end{array}$ & $2(7.4 \%)$ \\
\hline Otras & $\begin{array}{l}\text { - El miedo } \\
\text { - El amor por los animales } \\
\text { - El baile }\end{array}$ & $4(14.81 \%)$ \\
\hline Total & & $27(100 \%)$ \\
\hline
\end{tabular}

\subsection{El papel de la universidad en la protección ante a los comportamientos suicidas}

Se les preguntó a los participantes si consideraban que la universidad les ha servido de protección ante el comportamiento suicida. El 42,8\% (12) de los jóvenes respondió afirmativamente. Las tendencias principales de las respuestas se orientan en varias direcciones. La más generalizada se refiere al interés que suscita en ellos el universo de significaciones que encuentran en la universidad y el efecto protector que 
tiene el dirigir la atención y el deseo a sus procesos de formación: "los estudios son mi método de distracción ante todo pensamiento suicida."; "aquí despejo la mente y me distraigo estudiando"; "sí, ya que el ajetreo de las clases no permite que esas ideas lleguen, o si llegan no les prestó atención"; "entiendo que, de cierta manera, [la universidad] me ayudó porque conocí más mundo, vi personas que también pasaban por lo mismo que yo".

Otros acentúan el valor preventivo que tiene la formación y el fortalecimiento de su personalidad en la universidad: "le crea sentido de responsabilidad y se ayuda él y a los demás exponiendo sus ideas". Anudado a esto algunos subrayan la importancia del conocimiento de sí mismos que les posibilita la universidad: "Sí, mucha protección. Me ha ayudado a entender mucho mi persona y los demás"; y el apoyo que brindan demás actores del mundo universitario: "tuve profesores con los cuales compartí experiencias y sirvieron de consejeros al escuchar y comprender sin juzgar",

También el elemento teleológico, de representarse un futuro deseable, aparece subrayado en las respuestas de los estudiantes: "sí, pienso en que seré una profesional próximamente. Pienso en ese futuro que estoy construyendo hoy con mis estudios. Además de que los estudios son el foco de distracción ante todo problema".

\subsection{Comentarios de los estudiantes luego de diligenciar el instrumento}

Al final del instrumento aplicado hay una indicación que invita a los estudiantes a expresar un comentario libre. Algunos de ellos sugieren la importancia de que se les ofrezcan espacios orientados a la afirmación de la vida y la prevención de los comportamientos autodestructivos: "Creo que deben dar talleres de crecimiento porque mucha gente a nuestro alrededor pasa por situaciones similares y no tienen en quién confiar o un apoyo para que les de ese support"'; "sí, deseo saber si hay otros que sienten lo mismo que yo y deseo que nos brinden ayuda".

Otros estudiantes aprovechan el diligenciamiento del instrumento para advertir que los jóvenes que están pensando suicidarse, o desarrollando su plan de acción suicida, siempre dan señales que pueden contribuir a la prevención del fenómeno: "pienso que si mi madre y mi padre estuvieran más pendientes se hubieran percatado de tal situación porque las señales estaban, tanto como que yo siempre me ponía trapos para tapar las marcas recientes"; "pienso que dentro del tema del suicidio se de- ben considerar otros aspectos más allá del acto consciente del intento de quitarse la vida. El solo hecho de que exista el pensamiento o idea de que el morir nunca sería 
una solución a los problemas es un signo evidente de que algo anda mal"; "siempre pongo de mi parte para no tener ideas suicidas. Pero siempre estoy al pendiente o cuidado de las señales, ya que sé lo difícil y mal que es todo ese proceso y sufrimiento que causa no solo a mí sino también a mi familia"; "en el caso de mi amigo, pudimos haber evitado el que se quitara la vida porque esa noche estaba buscando con quien hablar. Las personas suicidas necesitan ser escuchadas y aconsejadas".

Los resultados de la investigación hasta aquí presentados nos permiten conocer y comprender los significados que los estudiantes participantes le adscriben a las ideaciones, los intentos suicidas y los suicidios, por experiencia tanto personal como indirectamente, y la manera como se construyen esos significados.

\section{Referencias}

Mead, G. H. (1999). Espíritu, persona y sociedad desde el punto de vista del conductismo social. Buenos Aires: Ed. Paidós

Morin, E. (1998). Introducción al pensamiento complejo. Barcelona, España: Gedisa.

Taha, N., Florenzano, R., Sieverson, C., Aspillaga, C. \& Alliende, L. (2011). La espiritualidad y religiosidad como factor protector en mujeres depresivas con riesgo suicida: Consenso de expertos. Revista chilena de neuropsiquiatría, 49(4), 347-360.

World Health Organization. (2014). Preventing Suicide: A Global Imperative. Disponible en: www.who.int/mental_health/suicide-prevention/world_report_2014/en/ 